\title{
Up-Regulation of HDAC6 Results in Poor Prognosis and Chemoresistance in Patients with Advanced Ovarian High-Grade Serous Carcinoma
}

\section{Mitsutake Yano}

Saitama Medical University International Medical Center

Mariko Miyazawa

Tokai University School of Medicine

\section{Naoki Ogane}

Ashigarakami Hospital

\section{Aiko Ogasawara}

Saitama Medical University International Medical Center

\section{Kosei Hasegawa}

Saitama Medical University International Medical Center

\section{Hisashi Narahara}

Oita University Faculty of Medicine

\section{Masanori Yasuda ( $\nabla$ m_yasuda@saitama-med.ac.jp)}

Saitama Medical University International Medical Center https://orcid.org/0000-0002-0769-360X

\section{Research}

Keywords: histone deacetylase 6, ovarian cancer: high-grade serous carcinoma, programmed cell death ligand-1, hypoxia inducible factor-1a, prognosis

Posted Date: July 7th, 2020

DOl: https://doi.org/10.21203/rs.3.rs-40241/v1

License: @ (i) This work is licensed under a Creative Commons Attribution 4.0 International License. Read Full License

Version of Record: A version of this preprint was published at Anticancer Research on March 1st, 2021. See the published version at https://doi.org/10.21873/anticanres.14927. 


\section{Abstract}

Background: Ovarian high-grade serous carcinoma (HGSC) gradually acquires chemoresistance after recurrence. In our previous study on ovarian clear cell carcinoma, histone deacetylase 6 (HDAC6) led to chemoresistance. This study aimed to evaluate HDAC6 as a predictor of chemoresistance and therapeutic target for ovarian HGSC.

Methods: We evaluated the clinical significance of HDAC6 as a predictor of prognosis and chemoresistance in HGSC. Immunohistochemical expressions of HDAC6, programmed cell death ligand-1 (PD-L1), and hypoxia inducible factor-1a (HIF-1a) were analyzed using clinical samples from 88 patients with ovarian HGSC. The clinicopathological characteristics were reviewed.

Results: Twenty-three patients had high HDAC6 expression; 10, positive PD-L1 expression; and 33, high HIF-1a expression. HDAC6 up-regulation was correlated with not undergoing interval debulking surgery $(p<0.001)$, incomplete surgical resection $(p=0.002)$, and frequent occurrence of stable disease/progressive disease according to the RECIST ( $p=0.005)$ criteria. On Kaplan-Meier analysis, high HDAC6 expression was significantly associated with decreased progression-free survival $(p=0.001)$ and overall survival $(p=0.008)$. On multivariate analysis, high HDAC6 expression (hazard ratio $=1.65 ; 95 \%$ confidence interval $1.03-2.66, p=$ 0.039 ) and surgery status were independent prognostic factors of progression-free survival. PD-L1 and HIF-1a expressions positively correlated with HDAC6.

Conclusion: HDAC6 is a potential therapeutic target since HDAC6 up-regulation might cause poor prognosis in patients with ovarian HGSC.

\section{Background}

Ovarian cancer is the leading cause of death owing to cancers of the female genital tract, with high-grade serous carcinoma (HGSC) being the most frequent histological type [1]. The most important prognostic factor for patients with HGSC is the tumor stage; approximately $75-80 \%$ of patients have advanced stage disease when they start showing symptoms, and only $<25 \%$ of patients with stage III/IV HGSC are curable using current therapies [2]. Typically, HGSC shows a good response to a combination of platinum and taxane agents, which is a standard chemotherapy regimen for epithelial ovarian cancers. However, HGSCs recur frequently and gradually acquire resistance to these standard chemotherapy regimens [2]. The most common molecular changes in HGSCs are TP53 alterations and inactivation (germline or somatic mutation or promoter methylation) of $B R C A 1$ and $B R C A 2$ in approximately $50 \%$ of HGSCs [3]. TP53 activation could sensitize cells to platinum-based chemotherapy, leading to cell cycle arrest and apoptosis [4]. Recently, new strategies have been devised for patients with ovarian cancer with BRCA mutations [5] or platinum-sensitive recurrence [6]. However, treatments for patients with TP53 mutations or those with platinum-resistant recurrence have yet to be developed.

Histone deacetylases (HDACs), which comprise 18 subtypes identified in humans, regulate tissue differentiation, apoptosis, migration, mitosis, and angiogenesis by chromatin-modification via the deacetylation of histone or non-histone proteins [7]. The inhibitors that target multiple HDACs exhibit cytotoxic effects in various cancers, including ovarian cancer [8], but they are limited in their application for cancer treatment because of various toxicities [9]. Therefore, more selective and effective HDAC inhibitors are required. Our previous study showed that high HDAC6 expression was an independent poor prognostic factor in epithelial ovarian cancer [10]. HDAC6 increases deacetylated a-tubulin levels, which up-regulate cancer cell growth by enhancing microtubule dynamics [11, 12]. HDAC6 down-regulation stabilizes p53 by increasing total p53 levels and p53 phosphorylation [13]. In contrast, HDAC6 up-regulation leads to platinum-resistance, and HDAC6 down-regulation enhances platinum agent-induced DNA damage and apoptosis [13]. Moreover, HDAC6 up-regulates several factors that cause chemoresistance, including hypoxia inducible factor1a (HIF-1a) [14] and programmed death ligand-1 (PD-L1) [15]. HDAC6-selective inhibitors were shown to be safe in clinical trials for multiple myeloma $[16,17]$. HDAC6-selective inhibitors also suppress the proliferation of ARID1A-mutated ovarian clear cell carcinoma and improved the survival of the tumor-bearing mice [18].

In the current study, using clinical samples of HGSC, we immunohistochemically analyzed the association between HDAC6 expression and HGSC prognosis, and aimed to evaluate HDAC6 as a predictor of chemoresistance and therapeutic target for ovarian HGSC. 


\section{Methods}

\section{Patients and samples}

All the methods, including the review of the electronic medical charts and pathological analysis, were performed in accordance with the 1975 Declaration of Helsinki after obtaining the approval of the institutional review board (IRB number, 16-257) and informed consent (or with a formal waiver of consent). Altogether, 88 patients with ovarian HGSC that was surgically resected and pathologically confirmed at the Saitama Medical University International Medical Centre between 2007 and 2017 were recruited. The clinicopathological characteristics of these patients were reviewed, including age, recurrence, progression-free survival (PFS), overall survival (OS), FIGO stage, treatment methods, surgical status (complete or incomplete resection), response evaluation criteria in solid tumors (RECIST) status [19], and chemotherapy response score (CRS) [20, 21]. The RECIST was used to stratify patients according to the following responses: complete response (CR), partial response (PR), stable disease (SD), and progressive disease (PD) by using computed tomography before and after chemotherapy [19]. Based on omental examination results, CRS was used to classify patients as follows: patients with CRS of 3 had a complete/near complete response; those with CRS of 2 had a partial response; and those with CRS of 1 had no or minimal response [20,21].

\section{Immunohistochemical staining}

Immunohistochemical expression of HDAC6 (polyclonal rabbit anti-HDAC6, 1:500, ab1440, Abcam, Cambridge, UK), PD-L1 (monoclonal rabbit anti-PD-L1, 1:100, 28-8 pharmDx, Dako North America, CA, USA), and HIF-1a (polyclonal rabbit anti-HIF-1a, 1:100, NB100-479, Novus Biologicals, CO, USA) was analyzed by using 4- $\mu \mathrm{m}$ serial sections of formalin-fixed paraffin-embedded blocks. Dako Autostainer Link 48 (Agilent technologies, CA, USA) was used per the manufacturer's protocol. The Target Retrieval Solution was applied for antigen retrieval at $98^{\circ} \mathrm{C}$ for 20 minutes. Sections were incubated with the primary antibodies at $25^{\circ} \mathrm{C}$ for 60 minutes, followed by incubation with the secondary antibodies (EnVision FLEX/HRP, Agilent technologies, CA, USA) at $25^{\circ} \mathrm{C}$ for 30 minutes. The chromogen reaction was performed with diaminobenzidine plus $\mathrm{H}_{2} \mathrm{O}_{2}$.

\section{Interpretation of immunohistochemical results}

One gynecologic oncologist (Mitsutake Yano) and one gynecologic pathologist (Masanori Yasuda), both of who were blinded to the clinicopathological characteristics, evaluated the degree of immunohistochemical staining (Figure 1). The following scoring system was used: $0 \%$ stained cells indicated negative staining; $1 \%-50 \%$ stained cells, mild staining; and $51 \%-100 \%$ stained cells, marked staining. To optimize the differences in PFS and OS, the raw data were binarized for statistical analysis. For HDAC6 and HIF-1a, marked expression was considered to indicate high expression, while completely negative and mild expression was considered low expression. For PD-L1, mild and marked expression was defined as positive, while completely negative expression was considered negative.

\section{Statistical analysis}

Fisher's exact test or Pearson's chi-squared test was used to analyze the correlation between immunohistochemical expressions and the clinicopathological characteristics. Univariate survival analysis was performed by generating Kaplan-Meier curves, and differences between the groups were assessed using the log-rank statistic. The Cox proportional hazards model was used to perform univariate and multivariate survival analyses. All analyses were performed using SPSS v24.0 (SPSS Inc., IL, USA). Pvalues $<0.05$ were considered statistically significant.

\section{Results}

\section{Patient characteristics and immunohistochemical expression}

Table 1 shows the characteristics of the 88 patients with HGSC. All the patients included in the study were Japanese. All patients underwent platinum-based systemic chemotherapy as neoadjuvant treatment; however, interval debulking surgery was not performed in 26 patients (30\%) because of unresectable lesions. Among the 88 patients, 23 patients (26.1\%) showed high HDAC6 expression, 10 patients (11.4\%) showed positive PD-L1 expression, and 33 patients (37.5\%) showed high HIF-1a expression. Table 2 shows the correlations between patient characteristics and immunohistochemical expression of HDAC6, HIF-1a, and PD-L1. High 
HDAC6 expression was significantly correlated with not undergoing interval debulking surgery $(p<0.001)$, incomplete surgical resection $(p=0.002)$, and frequently showing SD/PD according to the RECIST criteria $(p=0.005)$, but there was no significant correlation with CRS. A high expression of HIF-1 a was correlated with the recurrence $(p=0.029)$. There was no significant correlation between PD-L1 expression and the clinicopathological characteristics. HDAC6 expression showed significantly positive correlations with PD-L1 $(p=0.002)$ and HIF-1a $(p=0.008)$ expression. 


\begin{tabular}{|c|c|}
\hline Characteristic & $\mathrm{N}=88$ \\
\hline \multicolumn{2}{|l|}{ Age (years) } \\
\hline Median (range) & $61.1(41-82)$ \\
\hline$\leq 60$ & 38 \\
\hline$>60$ & 50 \\
\hline \multicolumn{2}{|c|}{ Cancer antigen $125(\mathrm{U} / \mathrm{mL})$} \\
\hline Median (range) & $2658(37-24,200)$ \\
\hline$\leq 500$ & $19(22 \%)$ \\
\hline$>500$ & $69(78 \%)$ \\
\hline \multicolumn{2}{|l|}{ Treatment } \\
\hline$N A C+I D S$ & $62(70 \%)$ \\
\hline NAC only & $26(30 \%)$ \\
\hline \multicolumn{2}{|l|}{ FIGO stage } \\
\hline III & $64(73 \%)$ \\
\hline IV & $24(27 \%)$ \\
\hline \multicolumn{2}{|l|}{ Surgery } \\
\hline Complete resection & $44(50 \%)$ \\
\hline Incomplete resection & $44(50 \%)$ \\
\hline \multicolumn{2}{|l|}{ RECIST status } \\
\hline $\mathrm{CR}$ & $14(16 \%)$ \\
\hline PR & $62(71 \%)$ \\
\hline SD & $5(6 \%)$ \\
\hline PD & $6(7 \%)$ \\
\hline \multicolumn{2}{|l|}{ CRS $(n=61)$} \\
\hline 1 & $9(14 \%)$ \\
\hline 2 & $16(26 \%)$ \\
\hline 3 & $36(60 \%)$ \\
\hline \multicolumn{2}{|l|}{ Recurrence } \\
\hline Present & 73 (83\%) \\
\hline Absent & $15(17 \%)$ \\
\hline \multicolumn{2}{|l|}{ Survival status } \\
\hline Dead & $46(52 \%)$ \\
\hline Alive & $42(48 \%)$ \\
\hline
\end{tabular}


Table 2

Clinicopathological characteristics and immunohistochemistry expressions in patients with high-grade serous carcinoma ( $N=88$ )

\begin{tabular}{|c|c|c|c|c|c|c|c|c|c|}
\hline \multirow[b]{2}{*}{ Characteristic } & \multicolumn{3}{|c|}{ HDAC6 expression } & \multicolumn{3}{|c|}{ HIF-1a expression } & \multicolumn{3}{|c|}{ PD-L1 expression } \\
\hline & Low & High & p-value & Low & High & p-value & Negative & Positive & p-value \\
\hline \multicolumn{10}{|l|}{ Age (years) } \\
\hline$\leq 60$ & 28 & 10 & 0.582 & 26 & 12 & 0.219 & 33 & 5 & 0.446 \\
\hline$>60$ & 37 & 13 & & 29 & 21 & & 45 & 5 & \\
\hline \multicolumn{10}{|c|}{ Cancer antigen $125(\mathrm{U} / \mathrm{mL})$} \\
\hline$\leq 500$ & 13 & 6 & 0.368 & 11 & 8 & 0.416 & 17 & 2 & 0.631 \\
\hline$>500$ & 52 & 17 & & 44 & 25 & & 61 & 8 & \\
\hline \multicolumn{10}{|l|}{ FIGO stage } \\
\hline III & 48 & 16 & 0.443 & 43 & 21 & 0.109 & 55 & 9 & 0.180 \\
\hline IV & 17 & 7 & & 12 & 12 & & 23 & 1 & \\
\hline \multicolumn{10}{|l|}{ IDS } \\
\hline Performed & 53 & 9 & $<0.001$ & 13 & 13 & 0.093 & 21 & 5 & 0.129 \\
\hline Not performed & 12 & 14 & & 42 & 20 & & 57 & 5 & \\
\hline \multicolumn{10}{|l|}{ Surgical status } \\
\hline Complete & 39 & 5 & 0.002 & 31 & 13 & 0.093 & 40 & 4 & 0.369 \\
\hline Incomplete & 26 & 18 & & 24 & 20 & & 38 & 6 & \\
\hline \multicolumn{10}{|l|}{ RECIST } \\
\hline CR/PR & 61 & 15 & 0.005 & 50 & 26 & 0.063 & 69 & 7 & 0.110 \\
\hline SD/PD & 4 & 7 & & 4 & 7 & & 8 & 3 & \\
\hline \multicolumn{10}{|l|}{ CRS $(n=61)$} \\
\hline $1=$ resistant & 7 & 2 & 0.482 & 7 & 2 & 0.425 & 8 & 1 & 0.833 \\
\hline 2 = intermediate & 15 & 1 & & 9 & 7 & & 15 & 1 & \\
\hline $3=$ sensitive & 32 & 4 & & 26 & 10 & & 34 & 2 & \\
\hline \multicolumn{10}{|l|}{ Recurrence } \\
\hline Present & 53 & 20 & 0.406 & 42 & 31 & 0.029 & 64 & 9 & 0.460 \\
\hline Absent & 12 & 3 & & 13 & 2 & & 14 & 1 & \\
\hline \multicolumn{10}{|l|}{ Survival status } \\
\hline Dead & 31 & 8 & 0.114 & 25 & 21 & 0.076 & 41 & 5 & 0.571 \\
\hline Alive & 34 & 8 & & 30 & 12 & & 37 & 5 & \\
\hline
\end{tabular}

Correlation between HDAC6, PD-L1, and HIF-1a expressions and survival

On Kaplan-Meier survival curves, high HDAC6 expression was significantly associated with a decrease in the PFS $(p=0.001$, Fig. 1A) and OS ( $p=0.008$, Fig. 1B). High HIF-1a expression was significantly associated with a decrease in the PFS $(p=0.006$, Fig. $1 C)$ and 
OS ( $p=0.033$, Fig. 1D). Positive PD-L1 expression was significantly associated with a decrease in the PFS $(p=0.029$, Fig. 1E) and OS ( $p<0.05$, Fig. $1 F)$. On univariate analysis using the Cox proportional hazards model, high HDAC6 expression, RECIST status, CRS, and surgery status were prognostic factors for the PFS and OS (Table 3). On multivariate analysis, high HDAC6 expression (hazard ratio $(\mathrm{HR})=1.65 ; 95 \%$ confidence interval $(\mathrm{Cl}) 1.03-2.66, p=0.039)$ and surgery status $(\mathrm{HR}=2.18 ; 95 \% \mathrm{Cl} 1.35-3.52, p=$ $0.002)$ were independent prognostic factors for the PFS. The surgery status $(\mathrm{HR}=2.45 ; 95 \% \mathrm{Cl} 1.33-4.51, p=0.004)$ was the only independent prognostic factor for the OS on multivariate analysis (Table 3).

Table 3

Univariate and multivariate analyses using the Cox proportional hazards model for patients with high-grade serous carcinoma

\begin{tabular}{|c|c|c|c|c|c|c|c|c|c|c|c|c|}
\hline \multirow[b]{2}{*}{ Variable } & \multicolumn{3}{|c|}{$\begin{array}{l}\text { Univariate analysis } \\
\text { (PFS) }\end{array}$} & \multicolumn{3}{|c|}{$\begin{array}{l}\text { Multivariate analysis } \\
\text { (PFS) }\end{array}$} & \multicolumn{3}{|c|}{$\begin{array}{l}\text { Univariate analysis } \\
\text { (OS) }\end{array}$} & \multicolumn{3}{|c|}{$\begin{array}{l}\text { Multivariate analysis } \\
\text { (OS) }\end{array}$} \\
\hline & $\mathrm{HR}$ & $\begin{array}{l}95 \% \\
\mathrm{Cl}\end{array}$ & $\begin{array}{l}\mathrm{p}- \\
\text { value }\end{array}$ & $\mathrm{HR}$ & $\begin{array}{l}95 \% \\
\mathrm{Cl}\end{array}$ & $\begin{array}{l}\mathrm{p}- \\
\text { value }\end{array}$ & $\mathrm{HR}$ & $\begin{array}{l}95 \% \\
\mathrm{Cl}\end{array}$ & $\begin{array}{l}\mathrm{p} \text { - } \\
\text { value }\end{array}$ & $\mathrm{HR}$ & $\begin{array}{l}95 \% \\
\mathrm{Cl}\end{array}$ & $\begin{array}{l}\mathrm{p}- \\
\text { value }\end{array}$ \\
\hline $\begin{array}{l}\text { Age ( } \leq 60 \\
\text { vs. } \\
>60 \text { years) }\end{array}$ & 0.97 & $\begin{array}{l}0.61- \\
1.54\end{array}$ & 0.893 & & & & 1.03 & $\begin{array}{l}0.57- \\
1.87\end{array}$ & 0.917 & & & \\
\hline $\begin{array}{l}\text { FIGO stage } \\
\text { (III vs. IV) }\end{array}$ & 1.48 & $\begin{array}{l}0.90- \\
2.43\end{array}$ & 0.120 & & & & 1.49 & $\begin{array}{l}0.81- \\
2.74\end{array}$ & 0.199 & & & \\
\hline $\begin{array}{l}\text { Surgery } \\
\text { (complete } \\
\text { vs. } \\
\text { incomplete } \\
\text { resection) }\end{array}$ & 2.39 & $\begin{array}{l}1.49- \\
3.84\end{array}$ & <. 001 & 2.43 & $\begin{array}{l}1.31- \\
4.52\end{array}$ & 0.005 & 2.50 & $\begin{array}{l}1.37- \\
4.59\end{array}$ & 0.003 & 2.45 & $\begin{array}{l}1.33- \\
4.51\end{array}$ & 0.004 \\
\hline $\begin{array}{l}\text { RECIST } \\
\text { status } \\
\text { (CR/PR vs. } \\
\text { SD/PD) }\end{array}$ & 2.69 & $\begin{array}{l}1.41- \\
5.13\end{array}$ & 0.003 & & & & 2.39 & $\begin{array}{l}1.06- \\
5.43\end{array}$ & 0.037 & & & \\
\hline $\begin{array}{l}\text { CRS }(1 / 2 \\
\text { vs. } 3)\end{array}$ & 1.43 & $\begin{array}{l}1.07- \\
1.90\end{array}$ & 0.017 & & & & 1.47 & $\begin{array}{l}1.01- \\
2.15\end{array}$ & 0.042 & & & \\
\hline $\begin{array}{l}\text { HDAC6 } \\
\text { expression } \\
\text { (low vs. } \\
\text { high) }\end{array}$ & 1.53 & $\begin{array}{l}1.17- \\
1.99\end{array}$ & 0.002 & 1.65 & $\begin{array}{l}1.03- \\
2.66\end{array}$ & 0.039 & 1.51 & $\begin{array}{l}1.10- \\
2.08\end{array}$ & 0.011 & & & \\
\hline $\begin{array}{l}\text { PFS, progre } \\
\text { Obstetrics } \\
\text { SD, stable } \\
\text { are shown }\end{array}$ & $\begin{array}{l}\text { on-fre } \\
\text { Gyne } \\
\text { ase; } \\
\text { old. }\end{array}$ & $\begin{array}{l}\text { urviv } \\
\text { logy; } \\
\text { prog }\end{array}$ & $\begin{array}{l}\text { S, ov } \\
\text { IST, R } \\
\text { ve di }\end{array}$ & $\begin{array}{l}\text { eE } \\
\text { RS }\end{array}$ & $\begin{array}{l}\mathrm{R}, \text { ha: } \\
\text { ation } \\
\text { moth }\end{array}$ & $\begin{array}{l}\text { ratio; } \\
\text { ria in } \\
\text { y res }\end{array}$ & $\begin{array}{l}\text { ide } \\
\text { im }\end{array}$ & $\begin{array}{l}\text { interv } \\
\text { CR, cc } \\
\text { DAC6, }\end{array}$ & $\begin{array}{l}\text { IIGO, Ir } \\
\text { lete re } \\
\text { tone d }\end{array}$ & $\begin{array}{l}\text { onal } \\
\text {;PR, } \\
\text { ase }\end{array}$ & $\begin{array}{l}\text { deratic } \\
\text { rtial re } \\
\text {-value }\end{array}$ & $\begin{array}{l}\text { of } \\
\text { onse; } \\
0.05\end{array}$ \\
\hline
\end{tabular}

\section{Discussion}

The current study showed that high HDAC6 expression was an independent poor prognostic factor in patients with advanced ovarian HGSC. HDAC6 up-regulation was significantly positively correlated with indicators of chemoresistance, such as surgical residual tumors and frequent SD/PD according to the RECIST criteria. Consistent with the results of our study, Wang et al. [13] had shown that HDAC6 up-regulation leads to resistance to platinum agents, and HDAC6 down-regulation enhances platinum agentinduced DNA damage and apoptosis. TP53 activation, the most common mutation in HGSC, could sensitize cells to platinum agents, leading to cell cycle arrest and apoptosis [4]. HDAC6 down-regulation stabilized p53 by increasing the total p53 levels and p53 phosphorylation [13]. Moreover, the deacetylation of alpha-tubulin, induced by HDAC6, decreases the effect of taxane agents as a microtubule-stabilizing agent (Fig. 2) [22]. When HDAC6 is blocked, the resistance to taxane agents is reversed in epithelial ovarian cancer $[22,23]$. These results suggest that HDAC6 up-regulation is among the refractory factors of standard platinum-based chemotherapy for HGSC.

Optional treatment agents for ovarian cancer include bevacizumab (anti-vascular endothelial growth factor [VEGF] therapy) and olaparib (Poly[ADP-ribose] polymerase [PARP] inhibitors) for BRCA mutant or platinum-sensitive recurrent tumors $[4,5]$ as well as pembrolizumab (PD-1/PD-L1 blockage) for microsatellite instability-high tumors [24]. The current study showed there was a positive correlation between HDAC6 and PD-L1 expression. HDAC6 inhibition enhanced the response to immunotherapy via PD-1/PD-L1 [25]. 
The anti-cancer effect of HDAC6 inhibitors was triggered by the G2/M cell cycle arrest, apoptosis, and loss of mitochondrial membrane potential via the decreased VEGF and PARP [26]. In the present study, the expression of HDAC6 and HIF-1a, an upstream factor of VEGF, showed a significantly positive correlation (Fig. 2). Therefore, HDAC6 could be a potential therapeutic target for HGSC that is resistant to standard and/or optional chemotherapy.

HDAC6-selective inhibitors exhibit an anti-tumor effect in several cancer cell lines [16, 26-28], and they are well tolerated with minimal toxicity observed in clinical trials [16]. The incidence of kidney failure [29] and peripheral neuropathy [30], which are common adverse effects caused by platinum and taxane agents, respectively, were reduced after using HDAC6-selective inhibitors. Therefore, we suggest that HDAC6 is a potentially important and safe therapeutic target for HGSC. Our study had several limitations. Although the sample size used in this study was small, the current study was the first to verify the correlation between HDAC6 and the indicators of chemoresistance by using clinical samples. Before drawing a conclusion based on the results of this study, further confirmation is warranted via a multi-ethnic population study and on a larger scale. Secondly, the present study consisted solely of qualitative IHC analysis and lacked both quantitative protein analysis and molecular correlations. Therefore, further studies are required to quantitatively analyze HDAC6 protein and mRNA expression.

\section{Conclusions}

In summary, HDAC6 up-regulation resulted in poor prognosis for patients with advanced ovarian HGSC because of chemoresistance. Therefore, HDAC6-selective inhibitors might be promising therapeutic agents for ovarian HGSC that is resistant to the current standard and/or optional chemotherapy regimens.

\section{List Of Abbreviations}

Cl Confidence interval

HGSC High-grade serous carcinoma

HR Hazard ratio

IRB Institutional review board

OS Overall survival

PFS Progression-free survival

VEGF Vascular endothelial growth factor

CR Complete response

CRS Chemotherapy response score

PD Progressive disease

PR Partial response

RECIST Response evaluation criteria in solid tumors

SD Stable disease

\section{Declarations}

\section{Acknowledgements}

We thank Tomomi Katoh, Kouichi Kamada, Yusuke Hosonuma, Satoshi Kanno, Nobuyuki Suzuki, and Yasuo Kamakura, Department of Pathology, Saitama Medical University International Medical Center, for their great technical support. In addition, we would like to thank Editage (www.editage.com) for English language editing.

Page 8/13 
MiY contributed to the conception, design, acquisition, analysis, interpretation of the data, and drafting of the manuscript. MaY contributed to the conception, design, and critical revision of the manuscript for the inclusion of important intellectual content and supervised the writing. $\mathrm{KH}$ contributed to the acquisition of data and supervision. AO contributed to the acquisition of data. HN contributed to the critical revision of the manuscript to ensure that important intellectual content was present. MarM and NO contributed to the conception and design of the manuscript to ensure that important intellectual content was present.

\section{Funding}

This study was funded by Hidaka Research Projects in the Saitama Medical University (Grant numbers: 30-D-1-3) and Grants-in-Aid from the Ministry of Education, Science, Sports and Culture of Japan (Research Project Numbers: 18K06997).

\section{Competing interests}

The authors declare no competing interests.

\section{Availability of data and materials}

All data generated or analyzed during this study are included in this published article.

\section{Ethics approval and consent to participate}

All the methods, including the review of the electronic medical charts and pathological analysis, were performed in accordance with the 1975 Declaration of Helsinki after obtaining the approval of the institutional review board (IRB number, 16-257) and informed consent (or with a formal waiver of consent).

\section{Consent for publication}

Consent for publication was obtained.

\section{References}

1. Heintz AP, Odicino F, Maisonneuve P, Quinn MA, Benedet JL, Creasman WT, et al. Carcinoma of the ovary. FIGO 26th Annual Report on the Results of Treatment in Gynecological Cancer. International journal of gynaecology and obstetrics: the official organ of the International Federation of Gynaecology and Obstetrics. 2006;95 Suppl 1:S161-92.

2. Bookman MA. First-line chemotherapy in epithelial ovarian cancer. Clin Obstet Gynecol. 2012;55:96-113.

3. Integrated genomic. analyses of ovarian carcinoma. Nature. 2011;474:609-15.

4. Kigawa J, Sato S, Shimada M, Kanamori Y, Itamochi H, Terakawa N. Effect of p53 gene transfer and cisplatin in a peritonitis carcinomatosa model with p53-deficient ovarian cancer cells. Gynecol Oncol. 2002;84:210-5.

5. Moore K, Colombo N, Scambia G, Kim BG, Oaknin A, Friedlander M, et al. Maintenance Olaparib in Patients with Newly Diagnosed Advanced Ovarian Cancer. N Engl J Med. 2018;379:2495-505.

6. Pujade-Lauraine E, Ledermann JA, Selle F, Gebski V, Penson RT, Oza AM, et al. Olaparib tablets as maintenance therapy in patients with platinum-sensitive, relapsed ovarian cancer and a BRCA1/2 mutation (SOLO2/ENGOT-Ov21): a double-blind, randomised, placebo-controlled, phase 3 trial. The Lancet Oncology. 2017;18:1274-84.

7. Falkenberg KJ, Johnstone RW. Histone deacetylases and their inhibitors in cancer, neurological diseases and immune disorders. Nature reviews Drug discovery. 2014;13:673-91.

8. Sonnemann J, Gange J, Pilz S, Stotzer C, Ohlinger R, Belau A, et al. Comparative evaluation of the treatment efficacy of suberoylanilide hydroxamic acid (SAHA) and paclitaxel in ovarian cancer cell lines and primary ovarian cancer cells from patients. BMC Cancer. 2006;6:183.

9. Modesitt SC, Sill M, Hoffman JS, Bender DP. A phase II study of vorinostat in the treatment of persistent or recurrent epithelial ovarian or primary peritoneal carcinoma: a Gynecologic Oncology Group study. Gynecol Oncol. 2008;109:182-6. 
10. Yano M, Yasuda M, Sakaki M, Nagata K, Fujino T, Arai E, et al. Association of histone deacetylase expression with histology and prognosis of ovarian cancer. Oncology letters. 2018;15:3524-31.

11. Miyake Y, Keusch JJ, Wang L, Saito M, Hess D, Wang X, et al. Structural insights into HDAC6 tubulin deacetylation and its selective inhibition. Nature chemical biology. 2016;12:748-54.

12. Hubbert C, Guardiola A, Shao R, Kawaguchi Y, Ito A, Nixon A, et al. HDAC6 is a microtubule-associated deacetylase. Nature. 2002;417:455-8.

13. Wang L, Xiang S, Williams KA, Dong H, Bai W, Nicosia SV, et al. Depletion of HDAC6 enhances cisplatin-induced DNA damage and apoptosis in non-small cell lung cancer cells. PloS one. 2012;7:e44265.

14. Yano M, Katoh T, Miyazawa M, Miyazawa M, Ogane N, Miwa M, et al. Clinicopathological correlation of ARID1A status with HDAC6 and its related factors in ovarian clear cell carcinoma. Scientific reports. 2019;9:2397.

15. P ML. PV, T K, M P, E S, J P, et al. Essential role of HDAC6 in the regulation of PD-L1 in melanoma. Molecular oncology. 2016;10:735-50.

16. Yee AJ, Bensinger WI, Supko JG, Voorhees PM, Berdeja JG, Richardson PG, et al. Ricolinostat plus lenalidomide, and dexamethasone in relapsed or refractory multiple myeloma: a multicentre phase 1b trial. The Lancet Oncology. 2016;17:156978.

17. Santo L, Hideshima T, Kung AL, Tseng JC, Tamang D, Yang M, et al. Preclinical activity, pharmacodynamic, and pharmacokinetic properties of a selective HDAC6 inhibitor, ACY-1215, in combination with bortezomib in multiple myeloma. Blood. 2012;119:2579-89.

18. Bitler BG, Wu S, Park PH, Hai Y, Aird KM, Wang Y, et al. ARID1A-mutated ovarian cancers depend on HDAC6 activity. Nat Cell Biol. 2017;19:962-73.

19. Eisenhauer EA, Therasse P, Bogaerts J, Schwartz LH, Sargent D, Ford R, et al. New response evaluation criteria in solid tumours: revised RECIST guideline (version 1.1). European journal of cancer (Oxford, England: 1990). 2009;45:228 - 47.

20. Bohm S, Faruqi A, Said I, Lockley M, Brockbank E, Jeyarajah A, et al. Chemotherapy Response Score: Development and Validation of a System to Quantify Histopathologic Response to Neoadjuvant Chemotherapy in Tubo-Ovarian High-Grade Serous Carcinoma. Journal of clinical oncology: official journal of the American Society of Clinical Oncology. 2015;33:245763.

21. Cohen PA, Powell A, Bohm S, Gilks CB, Stewart CJR, Meniawy TM, et al. Pathological chemotherapy response score is prognostic in tubo-ovarian high-grade serous carcinoma: A systematic review and meta-analysis of individual patient data. Gynecologic oncology. 2019.

22. Angelucci A, Mari M, Millimaggi D, Giusti I, Carta G, Bologna M, et al. Suberoylanilide hydroxamic acid partly reverses resistance to paclitaxel in human ovarian cancer cell lines. Gynecol Oncol. 2010;119:557-63.

23. Marcus Al, O'Brate AM, Buey RM, Zhou J, Thomas S, Khuri FR, et al. Farnesyltransferase inhibitors reverse taxane resistance. Cancer research. 2006;66:8838-46.

24. Marcus L, Lemery SJ, Keegan P, Pazdur R. FDA Approval Summary: Pembrolizumab for the Treatment of Microsatellite Instability-High Solid Tumors. Clinical cancer research: an official journal of the American Association for Cancer Research. 2019;25:3753-8.

25. Bae J, Hideshima T, Tai YT, Song Y, Richardson P, Raje N, et al. Histone deacetylase (HDAC) inhibitor ACY241 enhances antitumor activities of antigen-specific central memory cytotoxic $T$ lymphocytes against multiple myeloma and solid tumors. Leukemia. 2018;32:1932-47.

26. Dong J, Zheng N, Wang X, Tang C, Yan P, Zhou HB, et al. A novel HDAC6 inhibitor exerts an anti-cancer effect by triggering cell cycle arrest and apoptosis in gastric cancer. Eur J Pharmacol. 2018;828:67-79.

27. Azuma K, Urano T, Horie-Inoue K, Hayashi S, Sakai R, Ouchi Y, et al. Association of estrogen receptor alpha and histone deacetylase 6 causes rapid deacetylation of tubulin in breast cancer cells. Cancer research. 2009;69:2935-40.

28. Amengual JE, Johannet P, Lombardo M, Zullo K, Hoehn D, Bhagat G, et al. Dual Targeting of Protein Degradation Pathways with the Selective HDAC6 Inhibitor ACY-1215 and Bortezomib Is Synergistic in Lymphoma. Clinical cancer research: an official journal of the American Association for Cancer Research. 2015;21:4663-75. 
29. Tang J, Shi Y, Liu N, Xu L, Zang X, Li P, et al. Blockade of histone deacetylase 6 protects against cisplatin-induced acute kidney injury. Clinical science (London, England: 1979). 2018;132:339 - 59.

30. Krukowski K, Ma J, Golonzhka O, Laumet GO, Gutti T, van Duzer JH, et al. HDAC6 inhibition effectively reverses chemotherapyinduced peripheral neuropathy. Pain. 2017;158:1126-37.

\section{Figures}

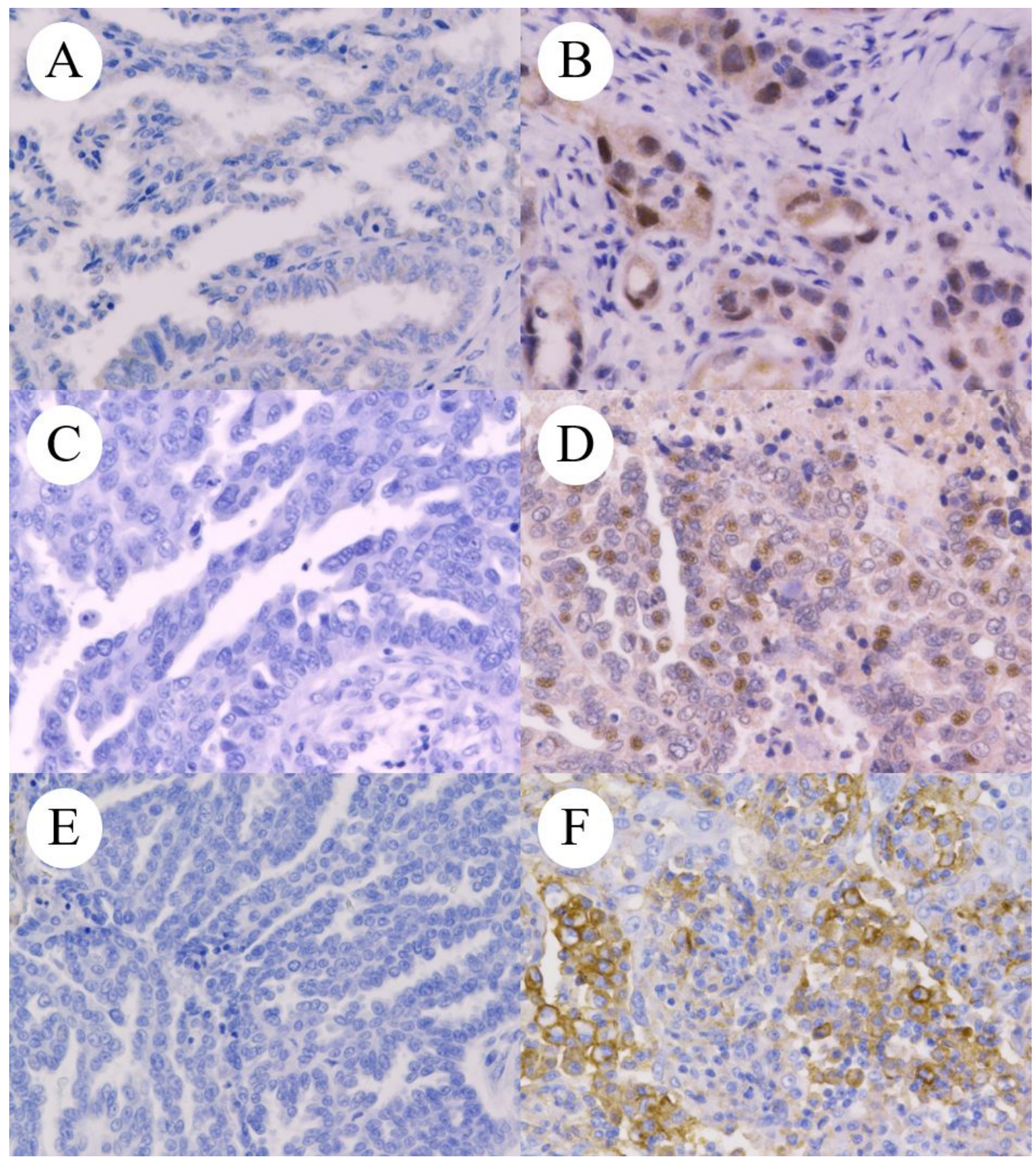

\section{Figure 1}

Kaplan-Meier survival analysis: HDAC6 (a, PFS; b, OS), HIF-1a (c, PFS; d, OS), and PD-L1 (e, PFS; f, OS). P-values were obtained using the log rank test. 

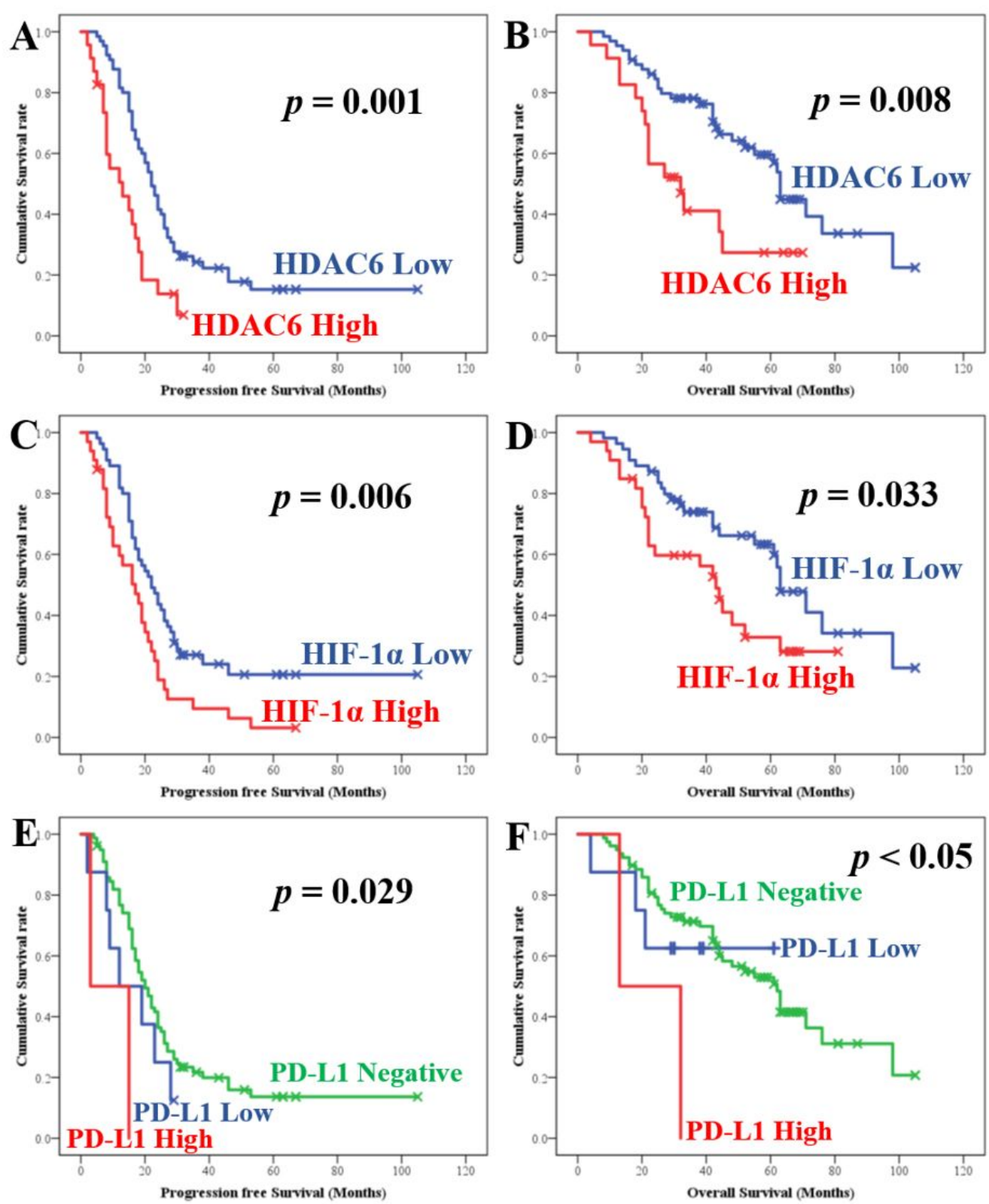

Figure 2

Scheme of HDAC6 functions: HDAC6 destabilizes TP53 by deacetylation and suppresses apoptosis. These effects of HDAC6 are responsible for platinum agent resistance. HDAC6 also leads to microtubule dynamics, tolerance to hypoxia and immunotherapy, and DNA repair dysfunction via tubulin, HIF-1a, PD-L1, and PARP. HDAC6 results in tolerance to taxane agents, cytotoxic T cells, immune-checkpoint inhibitors, bevacizumab, and olaparib. 


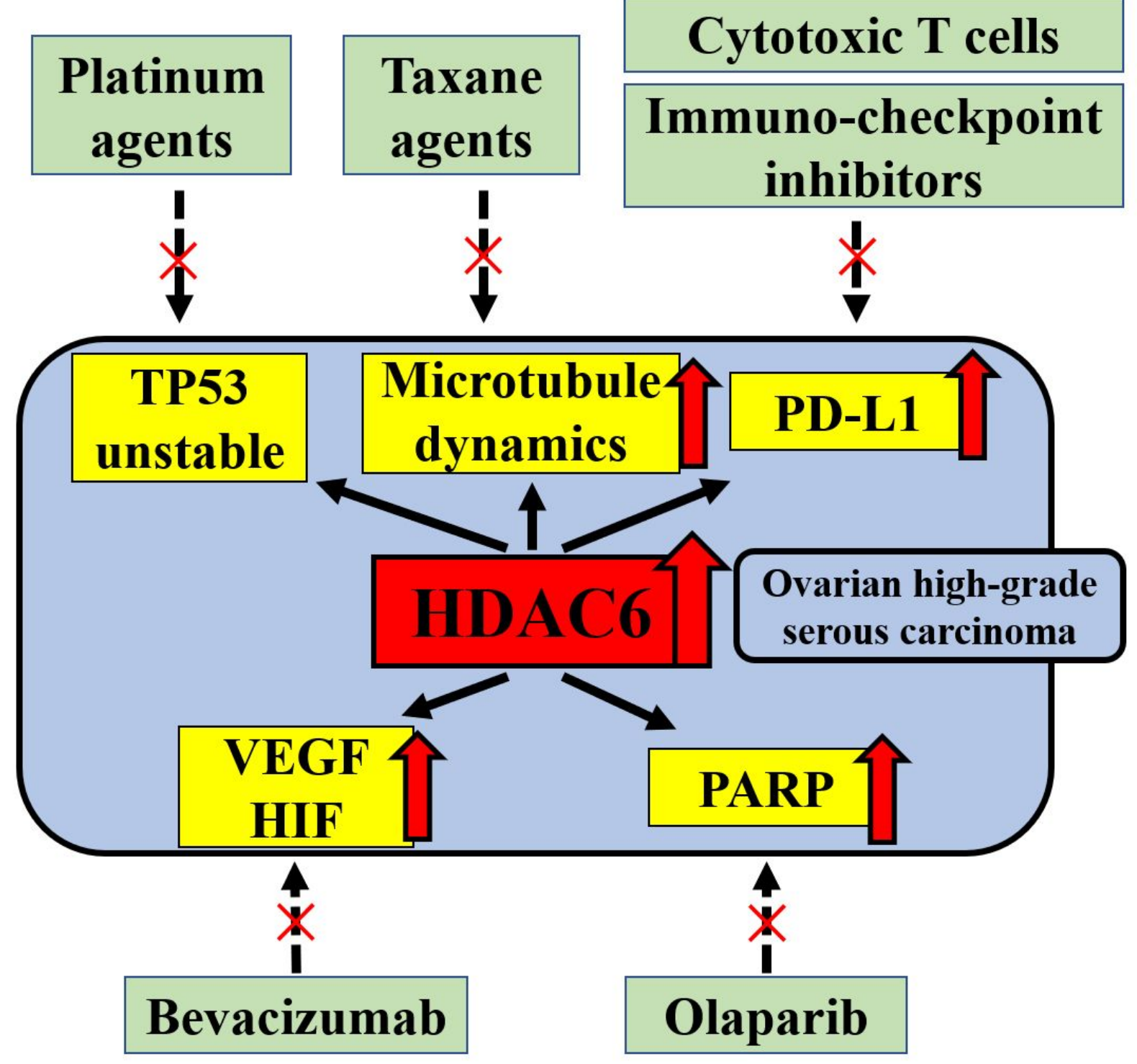

Figure 3

Immunohistochemical expression of HDAC6 (a, low; b, high), HIF-1a (c, low; d, high), and PD-L1 (e, negative; f, positive). 